\title{
Instability after hip hemiarthroplasty for femoral neck fracture: an unresolved problem
}

\author{
Amedeo Falsetto, MD \\ Johanna Dobransky, MSc \\ Cheryl Kreviazuk, BA \\ Steven Papp, MD MSc \\ Paul E. Beaulé, MD \\ George Grammatopoulos BSc, \\ MBBS, DPhil (Oxon)
}

Accepted Apr. 7, 2021

\author{
Corresponding to: \\ G. Grammatopoulos \\ Division of Orthopaedic Surgery \\ The Ottawa Hospital \\ 501 Smyth Rd., CCW 1638, \\ Ottawa ON K1H $8 \mathrm{~L} 6$ \\ ggrammatopoulos@toh.ca
}

Cite as: Can J Surg 2022 February 17; 65(1). doi: $10.1503 /$ cjs. 021220

\begin{abstract}
Background: The dislocated hip hemiarthroplasty (HA) remains a difficult condition to treat owing to frailty, comorbidity, poor quality of bone and soft tissues. We aimed to identify parameters contributing to instability following hip HA and describe the operative management and patient outcomes.
\end{abstract}

Methods: We retrospectively reviewed consecutive cases of all patients with hip fracture treated between 2004 and 2019 at a single tertiary care institution. We propensity matched patients with and without hip dislocations on a 1:2 basis for age, sex, and approach. We reviewed risk factors for HA dislocation, performed radiographic measurements, and recorded management of dislocation and further complications.

Results: Of the 1472 patients treated with HA, we included 18 patients (1.2\%) who sustained at least 1 dislocation in our analysis. Of the dislocations identified, 13 and 17 occurred within 1 and 3 months postoperative, respectively. The presence of dementia and low preoperative lateral centre-edge angle were associated with increased risk of dislocation. The 2-year mortality rate was significantly higher in the dislocation group $(n=9)$ than the control group $(n=2)(p=0.0003)$. Nine of $18(50 \%)$ patients were treated with an initial closed reduction; 5 of these $9(56 \%)$ sustained further dislocations and required additional treatment. Six of 18 cases were treated with a total hip arthroplasty after their first dislocation. By final follow-up, 2 of 18 patients had Girdlestone procedures.

Conclusion: This study highlights patient factors associated with increased dislocation risk following hip HA. A thorough preoperative assessment is indicated when presented with dislocated HA to prevent further complications.

Contexte : L'hémiarthroplastie (HAP) de la hanche disloquée reste un problème difficile à traiter en raison de la fragilité, des comorbidités et de la piètre qualité des os et des tissus mous. Nous avons voulu identifier les paramètres qui contribuent à l'instabilité après une hémiarthroplastie de la hanche et décrire sa prise en charge chirurgicale et les résultats chez les patients.

Méthodes : Nous avons passé en revue de manière rétrospective tous les cas de fracture de la hanche consécutifs traités entre 2004 et 2019 dans un seul hôpital de soins tertiaires. Nous avons assorti les patients affectés ou non par une dislocation de la hanche selon le score de propension dans un rapport 1:2 par âge, sexe et approche. Nous avons passé en revue les facteurs de risque de dislocation de l'HAP, procédé à des mesures radiographiques et noté le traitement des dislocations et autres complications.

Résultats : Parmi les 1472 patients ayant subi une HAP, nous avons inclus 18 patients $(1,2 \%)$ qui ont présenté au moins 1 dislocation dans notre analyse. Parmi les dislocations identifiées, 13 sont survenues à l'intérieur du premier mois suivant l'intervention et 17 à l'intérieur des 3 premiers mois suivant l'opération. La présence de démence et un angle VCE préopératoire réduit ont été associés à un risque accru de dislocation. Le taux de mortalité à 2 ans était significativement plus élevé dans le groupe ayant subi une dislocation $(n=9)$ que dans le groupe témoin $(n=2)(p=0,0003)$. Neuf patients sur $18(50 \%)$ ont été traités par réduction initiale fermée; 5 de ces 9 patients $(56 \%)$ ont subi d'autres dislocations et ont eu besoin de traitements additionnels. Six cas sur 18 ont été traités par arthroplastie totale de la hanche après leur première dislocation. À la fin du suivi, 2 patients sur 18 avaient subi une intervention de Girdlestone.

Conclusion : Cette étude met en lumière les facteurs propres aux patients qui sont associés à un risque accru de dislocation après une HAP de la hanche. Une évaluation préopératoire soigneuse est indiquée en présence d'une HAP disloquée pour prévenir d'autres complications. 
H ip hemiarthroplasty (HA) remains the standard of care for treatment of intracapsular hip fractures in elderly patients, ${ }^{1}$ and its use is on the rise because of the increasing incidence of femoral neck fractures. ${ }^{2}$ It is a core procedure in the orthopedic curriculum and performed by all subspecialty surgeons. The use of a large femoral head, akin to the native one, reduces the risk of instability compared with total hip arthroplasty. ${ }^{3}$ However, dislocation does still occur at a rate of $1 \%-6 \%{ }^{4-15}$ and remains a serious complication associated with increased anxiety, depression, soft tissue injury and lower EQ-5D scores. ${ }^{16}$ Hemiarthroplasty dislocation also carries a mortality rate of $65 \%$ at 6 months, rising to $75 \%$ if a second dislocation occurs. ${ }^{17}$

Given the high rate of associated morbidity and mortality, avoiding HA dislocation whenever possible is paramount. In addition, ensuring timely and appropriate treatment when this complication occurs is critical in the frail elderly patient population. ${ }^{18}$ The overall treatment of the dislocated hip HA has been shown to have a high failure rate, as it is complicated by patient frailty, soft tissue injury, and poor bone quality. ${ }^{19}$ To date, a limited number of studies compare the different treatment modalities and outcomes for a dislocated HA. As such, the aims of our study were to identify patient and surgical parameters associated with instability following HA and to describe the treatment provided for dislocated hips as well as patient outcomes following those treatments.

\section{Methods}

This was a research ethics board (REB)-approved retrospective, consecutive case series of all HAs performed at a large, academic, tertiary care centre. Our institutional data warehouse was queried to obtain a comprehensive list of all patients with femoral neck fractures receiving treatment between 2004 and 2019.

\section{Patients}

All patients with an intracapsular femoral neck fracture treated with an HA that dislocated were included in our study. Patients who sustained a dislocated HA after a revision surgery were excluded. Each case was manually reviewed by 2 independent reviewers in our electronic health records system.

\section{Patient parameters}

Data obtained from the electronic medical records included age, sex, American Society of Anesthesiologists (ASA) score $(\leq 2 \mathrm{v} . \geq 3)$, history of neurologic impairment, and dementia. Surgical factors collected and reviewed included the interval between admission and surgery (in hours), approach type (anterior, lateral or posterior), femoral fixation type (cemented or uncemented) and bearing diameter (in millimetres). The risk factors considered for analysis were based on previous literature. ${ }^{4-14,16,17}$

\section{Controls}

A propensity-matched cohort of patients with HA that had not dislocated during the study period was defined. Factors considered for the propensity matching included age, sex, and approach used for the hemiarthroplasty procedure. A 1:2 ratio of cases to controls was used in order to improve statistical power. Our control group was used to compare neurologic impairment, dementia status, time to surgery for hip fracture, fixation type, and bearing diameter. In addition, we recorded morbidity and mortality seen in this cohort.

\section{Treatment outcomes}

The time in days was documented from the index HA procedure to first dislocation. The treatment strategies were nonoperative (left dislocated), closed reduction, revision HA, revision to total hip arthroplasty (THA), and excision/Girdlestone arthroplasty. We collected data on the treatment provided for patients with dislocated HAs and the outcomes following those treatments, including number of dislocations, time to first dislocation, failure of initial treatment, complications of surgery, and time to death. We documented the final treatment decision for the current dislocation after a closed reduction was performed initially. We also reviewed whether or not the staff member deciding on the treatment modality was an arthroplasty-trained surgeon. Subsequent dislocations, complications and their treatments were also documented.

We noted deaths documented within our institution's electronic medical record and in regional obituaries to determine the mortality rate for all patients included in our study.

\section{Radiographic analysis}

Preoperative and postoperative anteroposterior pelvic radiographs were used to determine a number of anatomic factors, including the lateral centre-edge angle (LCEA) and the difference in femoral offset and leg length between the operated and contralateral side. All measurements were performed using previously described techniques and a validated software (Surgimap). Measurements were performed by a senior orthopedic resident. Measurements on 10 patients were repeated to test for intraobserver reliability, with excellent agreement (intraclass correlation coefficient $>0.98$ ).

\section{Outcome measures of interest}

Outcome measures of interest included medical and anatomic factors that differed between patients with dislocated HAs and controls. Complication, reoperation and 
mortality rates for both groups were identified. The association between different management options for the dislocated HA and outcome was tested.

\section{Statistical analysis}

Statistical analysis was performed using SPSS version 26 software (IBM Corp). Categorical and continuous variables were compared using the $\chi^{2}$ test and Mann-Whitney $U$ test, respectively, with significance set at $p<0.05$.

\section{Results}

\section{Study population}

Of the 1472 consecutive patients treated with HA for fractured femoral neck during the study period, 26 were documented to have sustained a dislocation in the hospital's data warehouse records. Six patients were excluded because the dislocation occurred following revision surgery; of these, 2 patients had an irrigation and débridement for periprosthetic joint infection of an HA that then dislocated, and 4 patients were excluded after dislocating their hemiarthroplasty which was treated previously for a

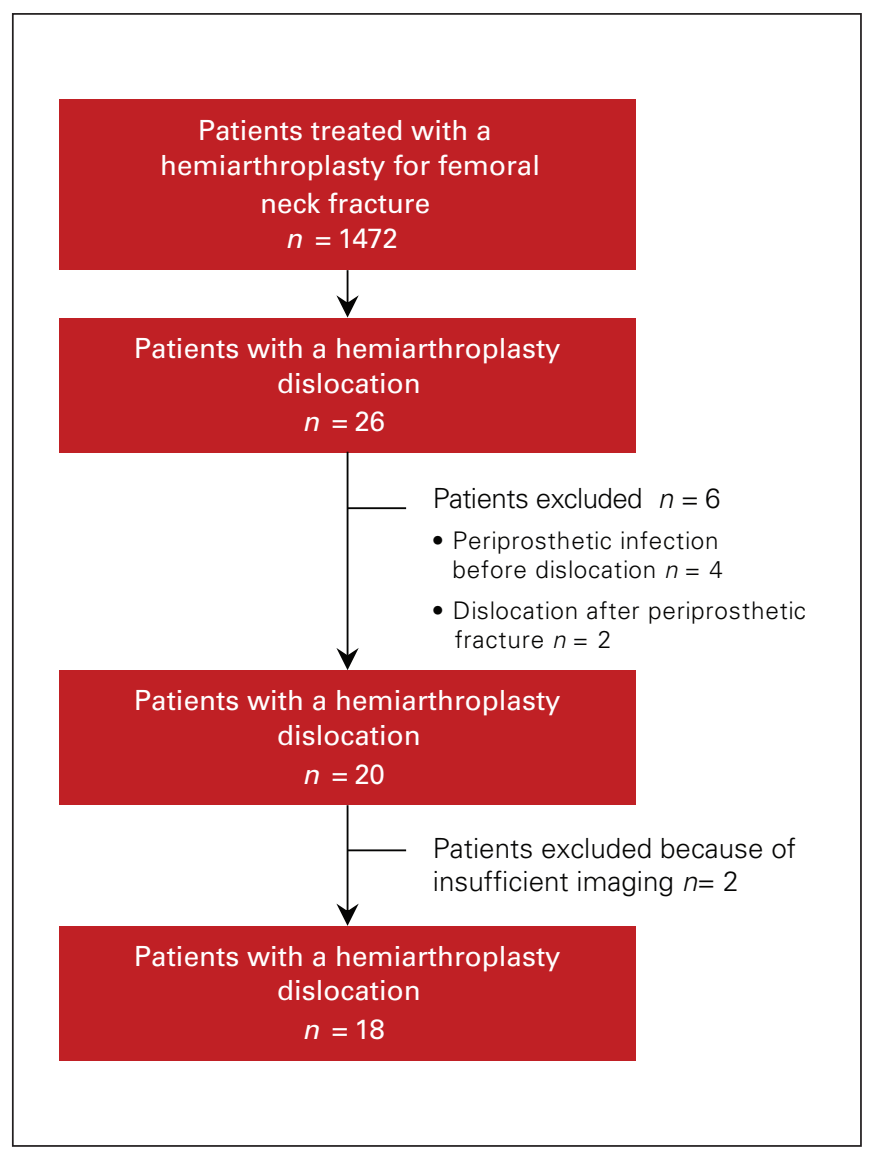

Fig. 1. Consort diagram showing study cohort selection, and inclusion and exclusion criteria. periprosthetic fracture. Of the 20 patients remaining, 2 more were excluded because they did not have any retrievable clinical or imaging data confirming the occurrence of a dislocation post-HA, leaving 18 patients $(1.2 \%)$ for our analyses (Figure 1 and Figure 2). We included 36 control patients for comparison. The cases and controls were well matched (Table 1).

The mean age of the 18 patients with dislocated HAs was $81.6 \pm 9.0$ years. The cohort was predominantly female $(n=15)$, and most of the patients had the HA implanted via a lateral approach $(n=14)$. Of the 18 dislocations identified, 4 (22\%) occurred within the admission for the index procedure; $9(50 \%)$ occurred within 1 month following the index procedure, and 17 (94\%) occurred within 3 months following the index procedure.

We identified 2 significant factors associated with increased risk of dislocation (Table 1). There was a significantly greater prevalence of dementia among patients with dislocated HAs than among those without dislocations $(11 / 18$ v. $10 / 36, p=0.022)$. In addition, the LCEA was significantly smaller in patients with dislocated HAs $(26.8 \pm 5.4$ v. $31.2 \pm 7.5, p=0.041)$ (Figure 3). There were no differences in leg length discrepancy and accuracy of offset reconstruction between the groups. The surgical approach and fixation method were not associated with dislocation risk. Radiographic assessments are summarized in Table 2.

\section{Treatment and outcome}

Nine $(50 \%)$ cases were treated initially with a closed reduction only (Figure 4A-C); of these, 5 (56\%) sustained further dislocations and required further treatment with either conversion to THA $(n=2)$, revision HA $(n=2$; increase in femoral head length after open reduction) or repeat closed reduction and no further revision $(n=1)$. Two patients underwent open reduction only owing to failed closed reductions, 1 of whom underwent further dislocation needing a THA. Seven patients were treated with a revision arthroplasty procedure after their first dislocation (6 THA and 1 revision HA) (Figure 4D-F); 3 sustained a further complication (2 dislocations, 1 periprosthetic joint infection with dislocation). Of the 3 patients with recurrent instability, 2 underwent a Girdlestone procedure and 1 underwent a revision THA of both components with a constrained liner and an increase in the anteversion of the femoral stem.

Arthroplasty surgeons were more likely to proceed with some form of arthroplasty-related procedure (i.e., revision HA or conversion to THA). Nonarthroplasty surgeons were more likely to perform a repeat closed reduction or an open reduction without revising the implants.

In the control group, only 1 patient had a complication (periprosthetic joint infection) requiring further surgery (débridement, antibiotics and implant retention). 


\section{Mortality}

The 3-month mortality rate was similar between groups; however, the 2-year mortality rate was significantly lower in the control group than in patients with dislocated HAs
$(2 / 36[5.6 \%]$ v. $9 / 18[50 \%], p=0.002)$. The mortality rate did not differ significantly between patients who had more than 1 dislocation $(p=0.453)$ and those who had only 1 ( $p=0.486)$, or between those who had further surgery $(p=0.343)$ and those who did not $(p=0.867)$.

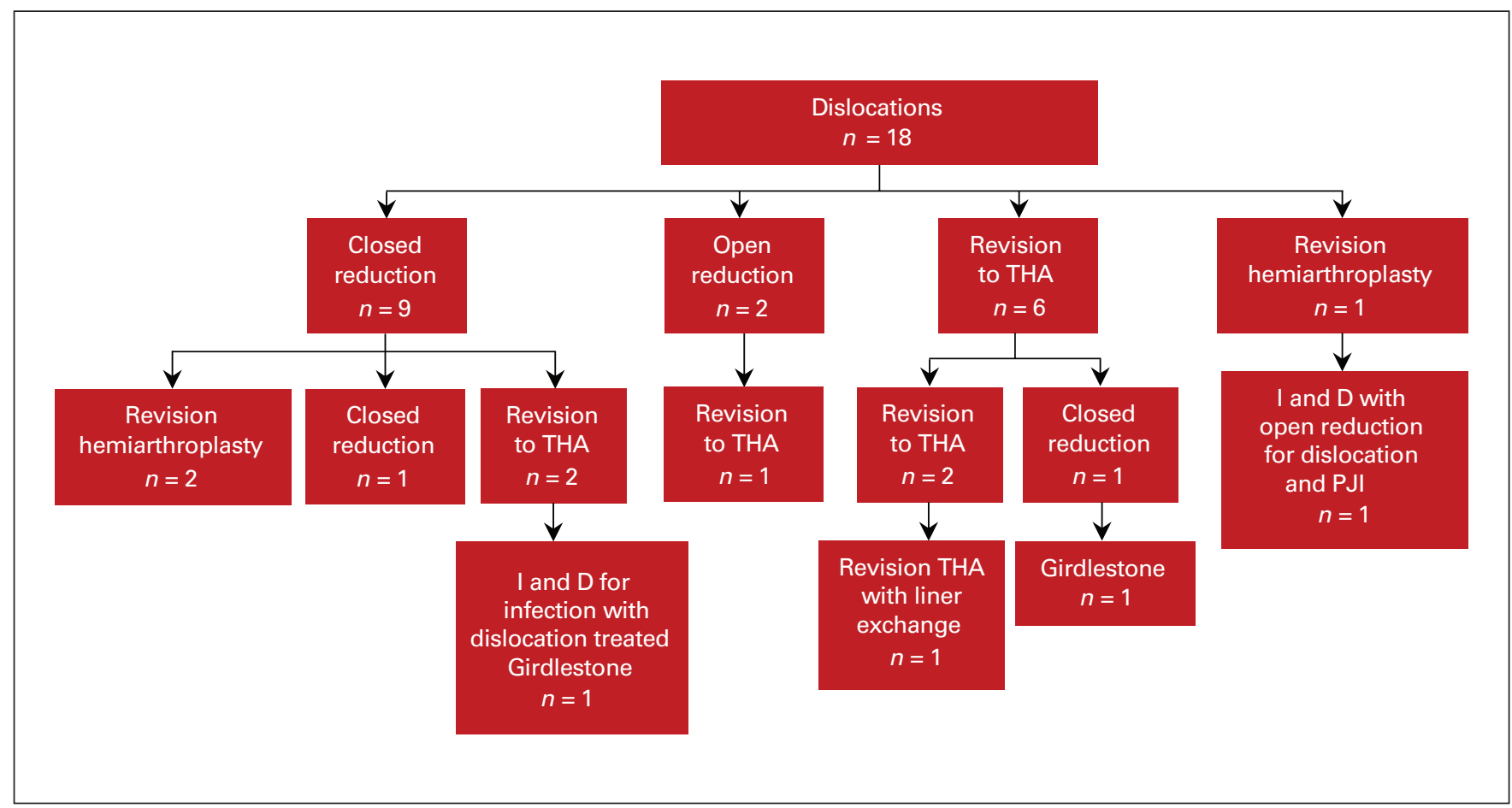

Fig. 2. Flow diagram illustrating the management of primary hip hemiarthroplasties and the associated outcome thereafter at the study's tertiary care centre. I and D = irrigation and débridement; THA = total hip arthroplasty.

\begin{tabular}{|c|c|c|c|c|}
\hline \multirow[b]{2}{*}{ Variable } & \multirow[b]{2}{*}{ Cohort } & \multicolumn{2}{|c|}{ Dislocated } & \multirow[b]{2}{*}{$p$ value } \\
\hline & & Yes $(n=18)$ & No $(n=36)$ & \\
\hline Age, yr, mean \pm SD & $82.1 \pm 9.87$ & $81.6 \pm 9.0$ & $82.4 \pm 10.4$ & 0.660 \\
\hline Sex, male:female & $11: 43$ & 3:15 & $8: 28$ & 0.633 \\
\hline \multicolumn{5}{|l|}{ Approach, $n(\%)$} \\
\hline Lateral & 46 (85.2) & 14 (77.8) & $32(88.9)$ & - \\
\hline Posterior & $8(14.8)$ & $4(22.2)$ & $4(11.1)$ & 0.279 \\
\hline \multicolumn{5}{|l|}{ ASA grade, $n(\%)$} \\
\hline$|\&| \mid$ & $3(6.4)$ & $1(8.33)$ & $2(5.7)$ & - \\
\hline III \& IV & $44(93.6)$ & $11(91.7)$ & 33 (94.3) & 0.749 \\
\hline Neurological impairment, yes:no & $8: 46$ & 5:13 & 3:33 & 0.058 \\
\hline Dementia, yes:no & $21: 32$ & 11:07 & $10: 25$ & $0.022^{*}$ \\
\hline Femoral fixation, cemented: pressfit & $5: 48$ & 1:17 & 4:31 & 0.608 \\
\hline Interval between admission and surgery, hr, mean $\pm \mathrm{SD}$ & $40.6 \pm 26.4$ & $44 \pm 18.8$ & $39.5 \pm 28.5$ & 0.296 \\
\hline Bearing size, $\mathrm{mm}$, mean $\pm \mathrm{SD}$ & $46.9 \pm 3.75$ & $46.8 \pm 3.4$ & $47.0 \pm 4.0$ & 0.962 \\
\hline Died within 3 mo, $n$ & 3 & 2 & 1 & 0.250 \\
\hline Died within $24 \mathrm{mo}, n$ & 11 & 9 & 2 & 0.0003 \\
\hline
\end{tabular}




\section{Discussion}

A dislocated hip HA is an uncommon event that typically occurs in the first 3 months following the procedure. The incidence in our centre $(1.2 \%)$ is in line with that reported in other series $(1 \%-7 \%))^{5,20,21}$ In order to have a large enough cohort for analysis, we reviewed cases over a 15 -year period.

Having established the study cohort, a propensitymatched control cohort was established to try and identify other patient or surgical factors to be considered, in addition to the factors used for the matching process, as female sex and posterior approach are well-established risk factors associated with instability. Two other factors (dementia and LCEA) were identified to be associated with increased risk of instability, both of which were patient-related. These findings are in line with those reported in the literature, which identified patient cognition, previous failed

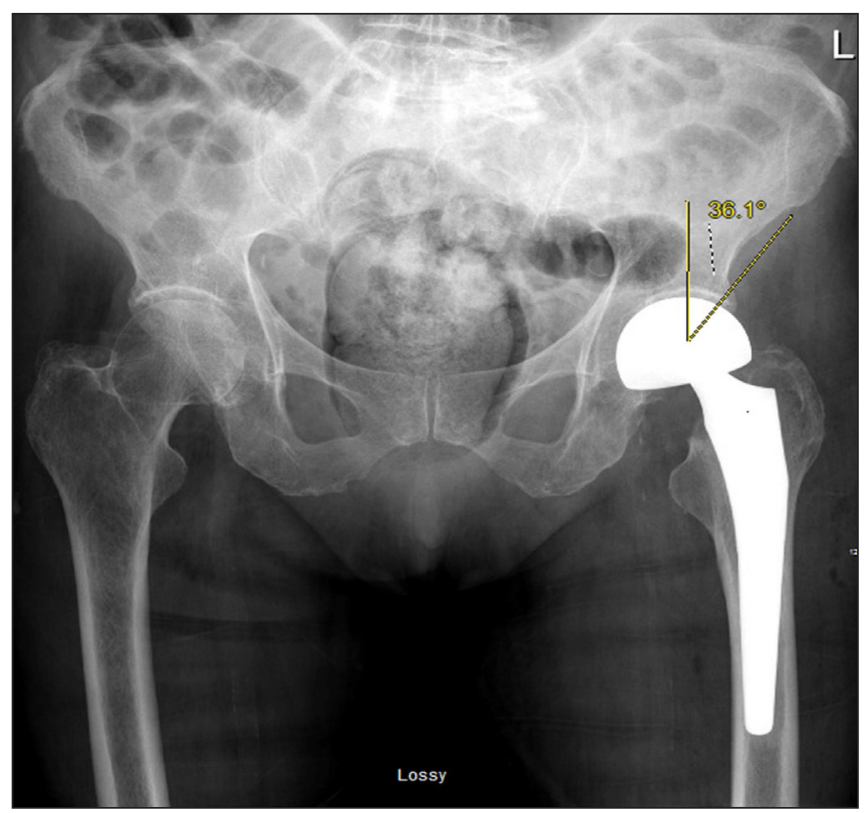

Fig. 3. Radiograph showing a normal lateral centre-edge angle. surgery, delay to surgery, surgical approach, and decreased femoral offset as factors most predictive of HA dislocations. ${ }^{16}$ The presence of dementia was associated with a 1.8 -fold increased risk of dislocation in this cohort. The increased association between dementia and instability was also noted by other authors; patients with dementia are likely to be unable to follow postoperative instructions and precautions pertinent to the procedure. ${ }^{22}$ The lower LCEA observed in patients with dislocated HAs indicates that the degree to which the femoral head is contained within the acetabulum is important for joint stability. Only 2 of the hips ( 1 case, 1 control) were dysplastic $\left(<20^{\circ}\right)$, and 14 hips (7 cases, 7 controls) showed signs of borderline dysplasia $\left(20^{\circ}-25^{\circ}\right) .^{23}$ Assessment of the LCEA preoperatively may help identify those at risk of instability.

Management of a dislocated hip HA is a challenging problem, highlighted by the lack of consensus on what the most appropriate management is and the sparse literature on the topic. We reviewed our experience with an aim of identifying factors associated with improved outcomes. Similar to the study by Gill and colleagues,${ }^{18}$ half of the cases in our study were treated with closed reduction only, and this was successful for more than half of them. However, the initial treatment offered for the other half of the patients was different. No patient underwent excision arthroplasty as their first procedure, and 6 of the remaining 9 patients underwent a conversion to THA. Contrary to previous reports, an excision arthroplasty was performed in only 2 patients (as the fourth procedure), while a conversion to a THA was performed in half of the patients. It is noteworthy that half of the patients in our cohort required several further surgeries - at least 3 in total, including the HA, with a fourth procedure required in 3 cases. Despite the differences in treatment modalities used compared with Gill and colleagues, ${ }^{18}$ the need for further surgery was equivalent (10/18 v. 19/43). Similarly, regardless of the initial treatment modality (whether closed reduction only or some form of open procedure), failure rates were equivalent. Overall, outcome is poor and probably reflect the host's functional reserve, capacity and

Table 2: Radiographic comparisons between patients with dislocated v. nondislocated hemiarthroplasty

\begin{tabular}{|c|c|c|c|}
\hline \multirow[b]{2}{*}{ Variable } & \multicolumn{2}{|c|}{ Dislocated, mean $\pm \mathrm{SD}$ (range) } & \multirow[b]{2}{*}{$p$ value } \\
\hline & Yes $(n=18)$ & No $(n=36)$ & \\
\hline Preoperative LCEA, ${ }^{\circ}$ & $26.8 \pm 5.4$ (19 to 36$)$ & $31.2 \pm 7.9(15$ to 46$)$ & 0.041 \\
\hline Femoral offset, mm & $39.8 \pm 7.4(21$ to 50$)$ & $40.2 \pm 7.9(19$ to 54$)$ & 0.891 \\
\hline Femoral offset, mm, contralateral side & $41.5 \pm 10.2$ (23 to 62$)$ & $40.8 \pm 8.3$ (25 to 59$)$ & 0.895 \\
\hline Leg length, mm & $48.7 \pm 6.5$ (37 to 62$)$ & $48.3 \pm 7.4$ (28 to 62$)$ & $>0.99$ \\
\hline Leg length, mm, contralateral side & $45.3 \pm 8.9$ (30 to 62$)$ & $45.6 \pm 7.8$ (30 to 60$)$ & 0.808 \\
\hline Difference in femoral offset, $\mathrm{mm}$ & $-2.63(-19$ to 15$)$ & $-0.63(-37$ to 22$)$ & 0.422 \\
\hline Leg length difference, $\mathrm{mm}$ & $3.00 \pm 6.6(-8$ to 15$)$ & $2.68 \pm 8.7(-20$ to 15$)$ & 0.807 \\
\hline
\end{tabular}




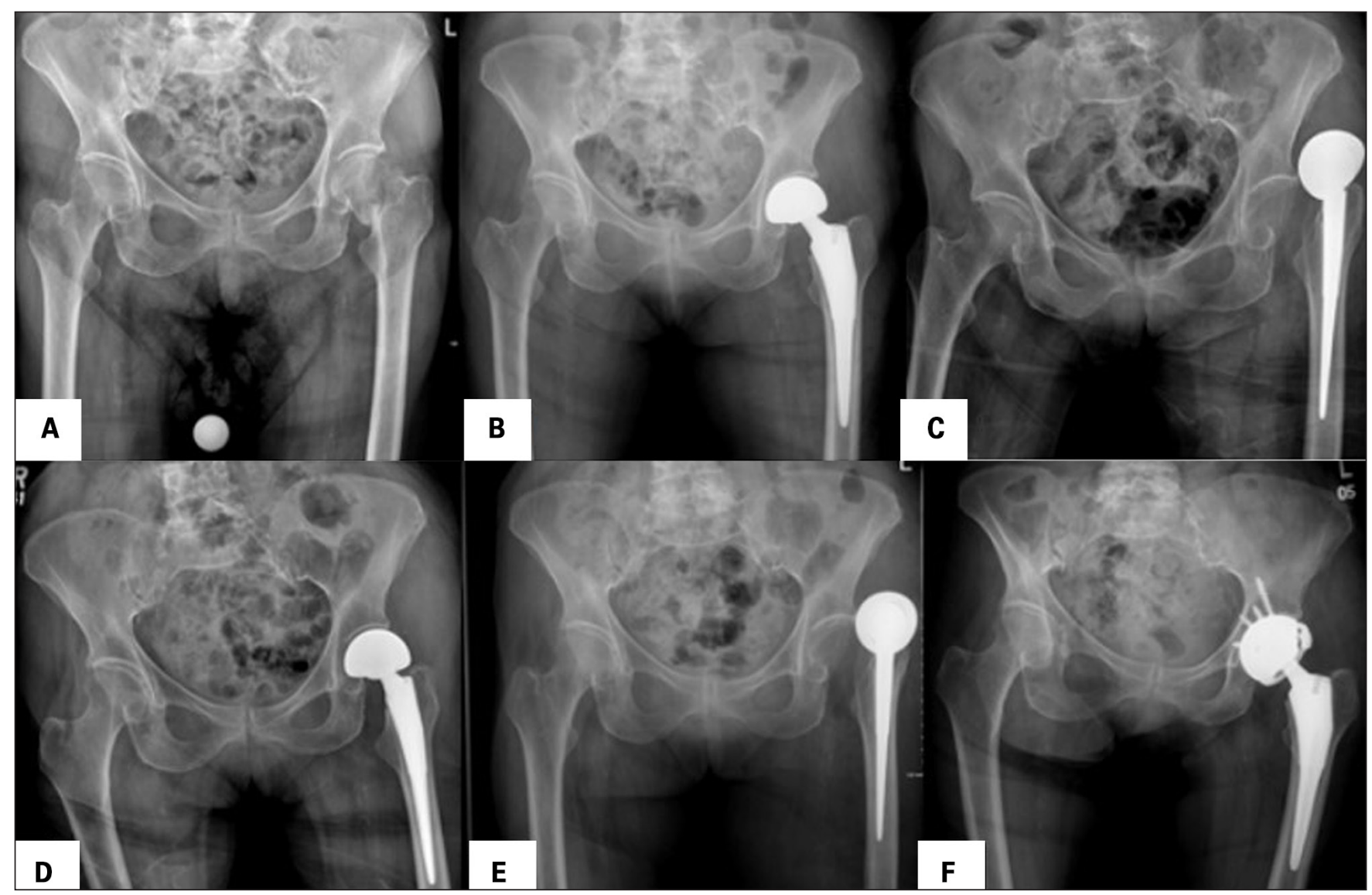

Fig. 4. Impact of low lateral centre-edge angle on hip stability. (A) anteroposterior radiograph of the pelvis showing a left femoral neck fracture. (B) Postoperative anteroposterior radiograph of the pelvis shoring adequate placement of a left hip hemiarthroplasty (HA). (C) Anteroposterior radiograph of the pelvis showing a left HA dislocation. (D) Radiograph of the pelvis showing a successful closed reduction. (E) Anteroposterior radiograph of the pelvis showing a redislocation of the left hip HA. (F) Anteroposterior radiograph of the pelvis showing revision of the implant to a total hip arthroplasty with constrained liner, given a failed closed reduction; the stem was deemed stable and, as such, not revised.

ability to recover from repeat procedures. It is thus unsurprising that mortality rates are significantly increased in this very frail cohort.

The low success rate following closed reduction only is concerning. Although evidence is weak, we would recommend the surgeon carefully assess these closed reduction cases intraoperatively to evaluate postreduction stability. Having an arthroplasty-trained surgeon present could be beneficial but is not always possible in smaller centres. If the hip shows any signs of instability, open exploration with conversion to THA, especially in cases with acetabular rim damage or acetabular under-coverage may be prudent. Consideration of dual mobility or constrained liner in patients with dementia who cannot follow postoperative instructions is also recommended. ${ }^{24-26}$

\section{Limitations}

This study has a number of limitations. First, it is retrospective and hence vulnerable to all limitations associated with such a design. Second, despite the 15 -year catchment period, only 18 patients were included in the dislocation cohort owing to the low incidence of this complication; therefore, this study may suffer from type-2 error. We aimed to improve statistical power by propensitymatching with a ratio of $1: 2$ with controls, which improves the ability to detect patient factors that influence the risk of instability, but this did not improve power in terms of management outcome. Finally, all radiographical analyses took place using anteropesterior radiographs; therefore, assessments of stem version were not possible.

\section{Conclusion}

This study highlighted certain patient factors associated with increased dislocation risk following hip HA that should alert surgeons before the HA in order to minimize risk of occurrence. Furthermore, this study emphasizes the complexity of management of instability. Once a dislocation occurs, patients often require more than 1 surgery, regardless of the initial management option used. A thorough preoperative assessment of the reasons for the 
dislocation and a plan to overcome these reasons may help reduce the incidence. We recommend an arthroplastytrained surgeon assist in the decision-making and treatment of this difficult complication.

Affiliation: From the Division of Orthopaedic Surgery, The Ottawa Hospital, Ottawa, Ont.

Competing interests: P. Beaulé reports grants from Zimmer Bioment and DePuy/Johnson \& Johnson; consultancy fees from MicroPort, Zimmer Biomet and Corin; and royalties from MicroPort, MarOrtho and Medacta, outside the submitted work. No other competing interests were declared.

Contributors: A. Falsetto, S. Papp, P. Beaulé and G. Grammatopoulos designed the study. A. Falsetto acquired and analysed the data, which J. Dobransky, C. Kreviazuk and G. Grammatopoulos also analysed. A. Falsetto and G. Grammatopoulos wrote the article, which all authors reviewed. All authors gave final approval of the article to be published.

Content licence: This is an Open Access article distributed in accordance with the terms of the Creative Commons Attribution (CC BY-NC-ND 4.0) licence, which permits use, distribution and reproduction in any medium, provided that the original publication is properly cited, the use is noncommercial (i.e., research or educational use), and no modifications or adaptations are made. See: https://creativecommons.org/licenses/by-nc-nd/4.0/

\section{References}

1. National Hip Fracture Database (NHFD) annual report. London (UK): Falls and Fragility Fracture Audit Programme. Royal College of Physicians; 2017. Available: https://www.nhfd.co.uk/files/2017ReportFiles/ NHFD-AnnualReport2017.pdf (accessed 2018 Aug. 16).

2. Health Quality Ontario; Ministry of Health and Long-Term Care. Quality-based procedures: clinical handbook for hip fracture. Toronto: Health Quality Ontario; 2013:1-98.

3. HEALTH Investigators; Bhandari M, Einhorn TA, Guyatt G, et al. Total hip arthroplasty or hemiarthroplasty for hip fracture. $N$ Engl 7 Med 2019;381:2199-208.

4. Madanat R, Mäkinen TJ, Ovaska MT, et al. Dislocation of hip hemiarthroplasty following posterolateral surgical approach: a nested case-control study. Int Orthop 2012;36:935-40.

5. Varley J, Parker MJ. Stability of hip hemiarthroplasties. Int Orthop 2004;28:274-7.

6. Suh KT, Kim DW, Lee HS, et al. Is the dislocation rate higher after bipolar hemiarthroplasty in patients with neuromuscular diseases? Clin Orthop Relat Res 2012;470:1158-64.

7. Unwin AJ, Thomas M. Dislocation after hemiarthroplasty of the hip: a comparison of the dislocation rate after posterior and lateral approaches to the hip. Ann R Coll Surg Engl 1994;76:327-9.

8. Petersen MB, Jørgensen HL, Hansen K, et al. Factors affecting postoperative mortality of patients with displaced femoral neck fracture. Injury 2006;37:705-11.
9. Ninh CC, Sethi A, Hatahet M, et al. Hip dislocation after modular unipolar hemiarthroplasty. 7 Arthroplasty 2009;24:768-74.

10. Blewitt N, Mortimore S. Outcome of dislocation after hemiarthroplasty for fractured neck of the femur. Injury 1992;23:320-2.

11. Sierra RJ, Schleck CD, Cabanela ME. Dislocation of bipolar hemiarthroplasty: rate, contributing factors, and outcome. Clin Orthop Relat Res 2006;442:230-8.

12. Barnes CL, Berry DJ, Sledge CB. Dislocation after bipolar hemiarthroplasty of the hip. 7 Arthroplasty 1995;10:667-9.

13. Noon AP, Hockings M, Warner JG. Dislocated Thompson hemiarthroplasty - the management of the recurrent dislocator. Injury 2005;36:618-21.

14. Salem KM, Shannak OA, Scammell BE, et al. Predictors and outcomes of treatment in hip hemiarthroplasty dislocation. Ann R Coll Surg Engl 2014;96:446-51.

15. Odumala AO, Iqbal MR, Middleton RG. Failure of closed reduction after dislocation of Austin Moore hemiarthroplasty: an analysis of risk factors a 6-year follow-up study. 7 Arthroplasty 2010;25:781-4.

16. Jones C, Briffa N, Jacob J, et al. The dislocated hip hemiarthroplasty: current concepts of etiological factors and management. Open Orthop f 2017;11:1200-12.

17. Blewitt N, Mortimore S. Outcome of dislocation after hemiarthroplasty for fractured neck of the femur. Injury 1992;23:320-2.

18. Gill JR, Kiliyanpilakkill B, Parker MJ. Management and outcomes of dislocated hip hemiarthroplasty. Bone foint f 2018;100-B:1618-25.

19. Enocson A, Pettersson H, Ponzer S, et al. Quality of life after dislocation of hip arthroplasty: a prospective cohort study on 319 patients with femoral neck fractures with a one-year follow-up. Qual Life Res 2009;18:1177-84.

20. Enocson A, Tidermark J, Tornkvist H, et al. Dislocation of hemiarthroplasty after femoral neck fracture. Acta Orthop 2008;79:211-7.

21. Figved W, Opland V, Frihagen F, et al. Cemented versus uncemented hemiarthroplasty for displaced femoral neck fractures. Clin Orthop Relat Res 2009;467:2426-35.

22. Li L, Ren J, Liu J, et al. What are the risk factors for dislocation of a hip bipolar hemiarthroplasty through the anterolateral approach? A nested case-control Study. Clin Orthop Relat Res 2016;474:2622-9.

23. Vaudreuil NJ, McMlincy MP. Evaluation and management of borderline dysplasia: moving beyond the lateral centre edge angle. Curr Rev Musculoskelet Med 2020;13:28-37.

24. Boukebous B, Boutroux P, Zahi R, et al. Comparison of dual mobility total hip arthroplasty and bipolar arthroplasty for femoral neck fractures: a retrospective case-control study of 199 hips. Orthop Traumatol Surg Res 2018;104:369-75.

25. Cha YH, Yoo JI, Kim JT, et al. Dual mobility total hip arthroplasty in the treatment of femoral neck fractures. Bone foint 7 2020;102B:1457-66.

26. Yassin M, Garti A, Khatib M, et al. Retentive cup arthroplasty in selected hip fracture patients - a prospective series with a minimum 3-year follow-up. Geriatr Orthop Surg Rehabil 2016;7:178-82. 